\title{
The Morphogenetic Effect of Sulphur-Containing Amino Acids, Glutathione and Iodoacetic Acid on Sclerotium rolfsii Sacc.
}

\author{
By I. CHET, Y. HENIS \\ Faculty of Agriculture, The Hebrew University \\ AND R. MITCHELL \\ Department of Biochemistry, Weizmann Institute of Science, \\ Rehovot, Israel
}

(Received 26 May 1966)

\begin{abstract}
SUMMARY
The sulphur-containing amino acids L-cysteine, L-cystine, L-methionine, L-homocysteine thiolactone, L-homocystine and glutathione at $10^{-4}$ to $10^{-5} \mathrm{M}$ inhibited sclerotial formation without inhibition of mycelial growth and induced basidia formation in the fungus Sclerotium rolfsii Sacc. Higher concentrations inhibited linear growth and production of sclerotia. The effect of L-cysteine was competitively antagonized by iodoacetic acid at a molar ratio of $30: 1$. Iodoacetic acid induced sclerotial formation at $3 \times 10^{-5}$ to $10^{-4} \mathrm{M}$, sclerotia being produced in circles around inoculation point. The possible role of $-\mathrm{SH}$ groups in the morphogenesis of $S$. rolfsii is discussed.
\end{abstract}

\section{INTRODUCTION}

Sclerotia are bodies produced by some septate fungi, they consist of an outer layer of thick-walled usually darkly pigmented cells which surround a mass of thinnerwalled closely interwoven hyphae (Townsend \& Willets, 1954). Because of their high resistance to chemical and biological degradation, many pathogenic fungi survive in soil as sclerotia. In spite of their biological and ecological significance, little is known about the factors which affect the production of sclerotia. The formation of microsclerotia by Verticillium albo-atrum is affected by light and an unidentified diffusible factor (Brandt, 1964). The production of sclerotia by Sclerotium rolfsii has been correlated with genetic processes (Higgins, 1927), growth under suboptimal conditions (Boyle, 1961) or inhibition of the growth of mycelial tips (Henis, Chet \& Avizohar-Hershenzon, 1965; Wheeler \& Waller, 1965). Attempts to control the production of sclerotia by $S$. rolfsii by sulphur-containing amino acids and related compounds led to the finding that these compounds not only affect sclerotidal production, but may induce the appearance of the sexual stage of this fungus, which is rather rare (West, 1947).

\section{METHODS}

The strain of Sclerotium rolfsii Sacc. used throughout these experiments was isolated from sugar beet. It was grown on a chemically defined medium solidified with agar prepared according to Joham (1943) and was composed of (g./l.): glucose, 
$40 ; \mathrm{K}_{2} \mathrm{HPO}_{4}, 0 \cdot 7 ; \mathrm{NH}_{4} \mathrm{NO}_{3}, 1 ; \mathrm{KCl}, 0 \cdot 15 ; \mathrm{MgSO}_{4} .7 \mathrm{H}_{2} \mathrm{O}, 0 \cdot 2 ; \mathrm{FeSO}_{4}, 0 \cdot 002 ; \mathrm{MnCl}_{2}$, $0.002 ; \mathrm{ZnSO}_{4}, 0.002$; thiamine chloride, 0.0001; Bacto agar (Difeo), 20; in distilled water 11 .; adjusted to $\mathrm{pH} 7 \cdot 0$. The medium autoclaved for $15 \mathrm{~min}$. at $121^{\circ}$.

The compounds to be tested were prepared at tenfold concentrations, sterilized by filtration through a Seitz filter and $1 \mathrm{ml}$. samples mixed with $9 \mathrm{ml}$. melted agar medium which was kept at $45^{\circ}$. Inocula were prepared from 3-day cultures, grown on defined medium agar at $30^{\circ}$. Agar discs $0.5 \mathrm{~cm}$. in diameter, covered with fungal mycelium, were cut by a sterile cork borer and placed at the centre of the defined medium agar plates containing the tested compounds. The incubation temperature was $30^{\circ}$. After incubation, sclerotia were collected and counted. Hyphal weight was determined by melting the agar, washing the remaining mycelium with hot water, drying it in the oven to constant weight in aluminium planchets at $60^{\circ}$, and weighing. Linear growth was determined by measuring the diameter of the growing colonies.

\section{RESULTS}

Effect of sulphur-containing amino acids and related compounds on the formation of sclerotia and mycelial growth of Sclerotium rolfsii

Plates containing defined medium agar with the tested compounds were inoculated with mycelial discs and incubated for 2 weeks at $30^{\circ}$. The sclerotia were collected and counted, hyphal weight and linear growth determined as described. The results are summarized in Fig. 1 and Table 1. L-Cysteine, L-cystine, L-methionine, L-homocysteine thiolactone, L-homocystine and glutathione at $10^{-4}$ to $10^{-5} \mathrm{M}$ inhibited sclerotia formation without affecting mycelial weight and its linear growth. Although mycelial weight was not affected significantly at concentrations greater than $10^{-4} \mathrm{M}$, both sclerotial formation and linear growth of mycelium were inhibited, the mycelium being denser and thicker than that of the control (Pl. 1, figs. 1, 2). Little inhibition of sclerotial formation and no effect on mycelial weight and linear growth were observed with $\beta$-mercaptoethanol, 2,3-dimercaptopropanol and thioglycollic (mercapto-acetic) acid, at $10^{-4}$ to $10^{-5} \mathrm{M}$. Higher concentrations (up

Table 1. The effect of some sulphur-containing compounds on linear growth and mycelial weight of Sclerotium rolfsii

Incubation time: 7 days. Each value represents an average of 10 replicates.

\begin{tabular}{|c|c|c|c|c|c|c|}
\hline \multirow[b]{3}{*}{ Compound } & \multicolumn{6}{|c|}{ Concentration of sulphur compound (M) } \\
\hline & \multicolumn{2}{|c|}{$10^{-4}$} & \multicolumn{2}{|c|}{$10^{-3}$} & \multicolumn{2}{|c|}{$10^{-2}$} \\
\hline & $\begin{array}{c}\text { Colony } \\
\text { diameter } \\
(\mathrm{mm} .)\end{array}$ & $\begin{array}{c}\text { Dry } \\
\text { weight } \\
\text { (mg./ } \\
\text { plate) }\end{array}$ & $\begin{array}{c}\text { Colony } \\
\text { diameter } \\
(\mathrm{mm} .)\end{array}$ & $\begin{array}{l}\text { Dry } \\
\text { weight } \\
\text { (mg./ } \\
\text { plate) }\end{array}$ & $\begin{array}{l}\text { Colony } \\
\text { diameter } \\
(\mathrm{mm} .)\end{array}$ & $\begin{array}{c}\text { Dry } \\
\text { weight } \\
\text { (mg./ } \\
\text { plate) }\end{array}$ \\
\hline L-Methionine & $90^{*}$ & 85 & 85 & 27 & 65 & 25 \\
\hline L-Cysteine & 90 & 130 & 71 & 245 & 42 & 117 \\
\hline L-Cystine & 90 & 25 & 74 & 69 & 46 & 60 \\
\hline Glutathione & 90 & 155 & 90 & 126 & 57 & 60 \\
\hline L-Homocystine & 90 & 93 & 90 & $\mathbf{5 5}$ & - & - \\
\hline L-Homocysteine thiolactone & 90 & 154 & 90 & 130 & 71 & 137 \\
\hline Control & 90 & 145 & & & & \\
\hline
\end{tabular}

* Colony diameter equal to that of the Petri dish at time of estimation. 
to $10^{-2} \mathrm{M}$ ) inhibited both linear growth and sclerotial formation. No inhibition was observed at these concentrations with L-histidine, L-tyrosine, glycine, $\mathrm{L}$-threonine, L-alanine, L-phenylalanine, L-asparagine, L-lysine or L-serine. In effective treatments at concentrations of $10^{-5}$ to $10^{-3} \mathrm{M}$ formation of sclerotia was only temporarily arrested, lasting for 2 or 3 weeks; at $10^{-2} \mathrm{M}$ both restriction of mycelial linear growth and permanent inhibition of sclerotial formation occurred.

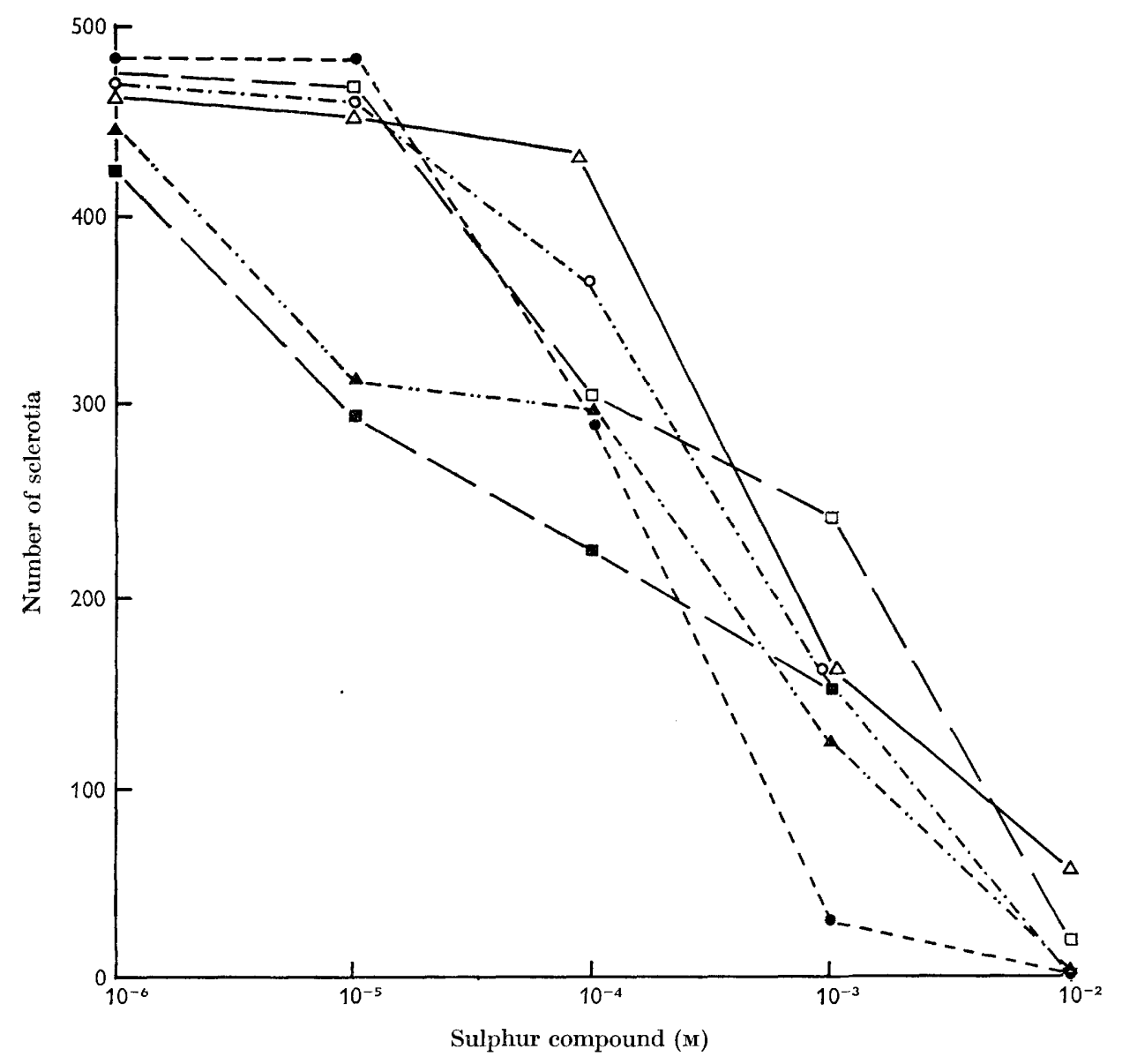

Fig. 1. Effect of some sulphur-containing compounds on production of sclerotia by

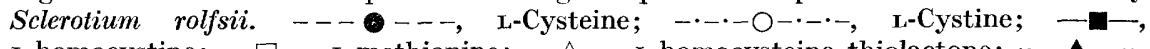
L-homocystine; - $\square-$, L-methionine; $-\triangle-$, L-homocysteine thiolactone; $\cdot-\mathbf{\Delta}-\cdot \cdot$ glutathione. Control: 490 sclerotia. Incubation: 7 days at $30^{\circ}$. Each value represents an average of 10 replicates.

Effect of sulphur-containing amino acids and related compounds on the formation of the sexual stage of Sclerotium rolfsii

In general, compounds which inhibited sclerotial formation without inhibiting linear mycelial growth stimulated the appearance of the sexual stage of Sclerotium rolfsii (Fig. 2). Basidia were formed mainly on side walls of the Petri dishes, the mycelium in these areas becoming very dense, yellow-cream in colour and typically 
odorous. The cream-coloured dense mycelium was sectioned by means of an ice microtome (Reichert Optical Works, Austria) to a width of $10 \mu$ and examined by a phase-contrast microscope. Basidia, sterigmata and basidiospores typical of the perfect stage of $\boldsymbol{S}$. rolfsii (West, 1947) were observed.

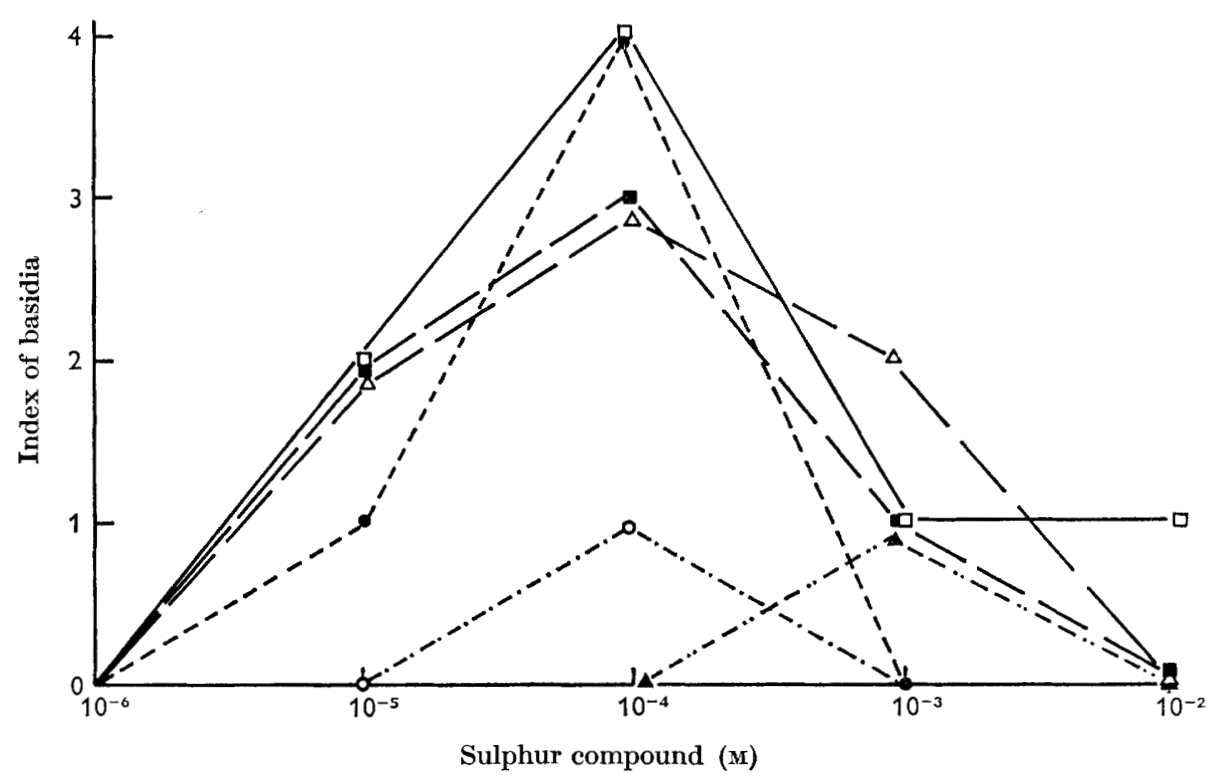

Fig. 2. Effect of some sulphur-containing compounds on production of basidia by Sclerotium rolfsii. Index of basidia is based on an arbitrary scale: from zero, no basidia, to 4, maximal amount of basidia. Legend, conditions and replicates, as for Fig. 1. Control: no basidia.

\section{Effect of iodoacetic acid on the production of sclerotia by Sclerotium rolfsii}

Because of the inhibitory effect of sulphydryl-containing amino acids on the production of sclerotia by Sclerotium rolfsii, it seemed of interest to examine the possible stimulatory effect of $-\mathrm{SH}$ antagonists on production of sclerotia. The effect of iodoacetic acid, L-cysteine and of mixtures of these compounds on sclerotial production by $S$. rolfsii is shown in Pl. 1. The optimal concentration of iodoacetic acid for sclerotial formation was $10^{-4} \mathrm{M}$. Higher concentrations $\left(5 \times 10^{-3} \mathrm{M}\right.$ or more) inhibited mycelial growth. Whereas the total numbers of sclerotia produced on plates containing iodoacetic acid were not significantly higher than that of the controls, the sclerotia were produced earlier ( $30 \mathrm{hr}$ as compared with $4-5$ days), and at the mycelial edges only, in concentric circles around the initial inoculum (Pl. 1, fig. 3), several circles of sclerotia, produced at intervals, being formed around the inoculum.

Both inhibition of mycelial growth and concentric production of sclerotia by iodoacetic acid was prevented by the addition of L-cysteine to the medium. At effective concentrations, a molar ratio of 30:1 of L-cysteine:iodoacetic acid was required for the complete mutual elimination of their effects. 


\section{DISCUSSION}

Environmental factors which have been reported to affect sporulation, spore germination and sclerotial formation in fungi, include $\mathrm{CO}_{2}, \mathrm{~N}_{2}$, vitamins, $\mathrm{pH}$ value, light, temperature, humidity, and 'atmospheric conditions' (Baldwin \& Rusch, 1965). The effect of sulphur-containing amino acids on vegetative form changes in fungi has been shown by Nickerson \& Falcone (1956), Nickerson (1963) and Nickerson \& Bartnicki-Garcia (1964). A stimulatory effect of sulphur-containing amino compounds on the formation of the perfect stage of Aphanomyces root rot has been also shown (Papavizas \& Davey, 1963). However, no information is available about the effect of sulphur compounds on the formation of sclerotia and basidia in fungi.

In testing the effect of amino acids on the formation of sclerotia and basidia in Sclerotium rolfsii only the sulphur-containing amino acids, especially L-cysteine, were active. Their addition to the medium at $10^{-4}$ to $10^{-5} \mathrm{M}$ resulted in decreased formation of sclerotia by $S$. rolfsii, without affecting mycelial weight and its linear growth, and in the induction of the production of basidia. However, other -SHcontaining compounds such as $\beta$-mercaptoethanol, 2,3-dimercaptopropanol and thioglycollic acid were much less active. The morphogenetic effect of sulphurcontaining amino acids and glutathione on the formation of sclerotia and basidia, does not necessarily mean that the same mechanism is involved.

If the intracellular concentration of - $\mathrm{SH}$ groups is a critical factor in the morphogenesis of Sclerotium rolfsii then it might be possible to induce sclerotial formation by a -SH antagonist such as iodoacetic acid. Indeed, the addition of $10^{-4} \mathrm{M}$ iodoacetic acid resulted in stimulation of sclerotial formation within $30 \mathrm{hr}$ from inoculation time. However, induction was limited to hyphal tips in the periphery of the fungal colony, the sclerotia forming a circle around the inoculation point. Moreover, the linear growth of the vegetative mycelium continued and new circles of sclerotia were formed around the first one (Pl. 1, fig. 3). Thus, iodoacetic acid enhanced sclerotial formation and changed the distribution of sclerotia on the agar plate. These phenomena may be connected with specific concentrations of iodoacetic acid at the mycelial tips, which result in a lower intracellular concentration of - SH groups. It seems now that inhibition of linear growth per se does not induce sclerotial formation, since both L-cysteine and iodoacetic acid inhibited linear mycelial growth at $10^{-2} \mathrm{M}$ and $5 \times 10^{-3} \mathrm{M}$, respectively; but whereas L-cysteine inhibited sclerotial formation as well, iodoacetic acid induced it.

Iodoacetic acid and L-cysteine competitively antagonized each other at a ratio of $1: 30$. This high ratio may be due to differences in permeability or in reaction rate inside the hyphal cells. The rate of reaction between these compounds at the $\mathrm{pH}$ value of the growth medium (7.0) is relatively slow (Cecil \& McPhee, 1959).

The perfect stage of Sclerotium rolfsii Sacc. (Pellicularia rolfsii) is rather rare (West, 1947) and no information is available about the factors involved in its formation. We believe that this is the first instance of a stimulation of the appearance of the perfect basidial stage of this fungus on an artificial growth medium.

This work was supported by Grant No. FG-Is-160 from the U.S. Department of Agriculture. The technical assistance of Mrs Zehava Shua is greatly acknowledged. 


\section{REFERENCES}

BaLdwin, H. H. \& RUSCH, H. P. (1965). The chemistry of differentiation in lower organisms. A. Rev. Biochem. 34, 565 .

Boyle, L. W. (1961). The ecology of Sclerotium rolfsii with emphasis on the role of saprophytic media. Phytopathology 51, 117.

BrandT, W. H. (1964). Morphogenesis in Verticillium; a self-induced, non-hereditary variation in colour form. Am. J. Bot. 51, 8.

CECIL, R. \& MCPHeE, J. R. (1959). The sulfur chemistry of proteins. Protein Chem. 14, 255.

Henis, Y., Chet, I. \& Avizohar-Hershenzon, Z. (1965). Nutritional and chemical factors involved in mycelial growth and production of sclerotia by Sclerotium rolfsii in artificial medium and amended soil. Phytopathology 55, 87.

Higgins, B. B. (1927). Physiology and Parasitism of Sclerotium rolfsii Sacc. Phytopathology 17,417 .

Jонам, H. E. (1943). A nutritional study of the fungus Sclerotium rolfsii. M.Sc. thesis. $A$ and $M$ College of Texas.

Nickerson, W. J. (1963). Symposium on biochemical bases of morphogenesis in fungi. IV. Molecular bases of form in yeasts. Bact. Rev. 27, 305.

Nickerson, W. J. \& Bartnicki-Garcia, S. (1964). Biochemical aspects of morphogenesis in algae and fungi. A. Rev. Plant Physiol. 15, 327.

Nickerson, W. J. \& Falcone, G. (1956). Identification of protein disulfide reductase as a cellular division enzyme in yeasts. Science 124, 722.

Papavizas, G. C. \& Davey, C. B. (1963). Effect of sulfur containing amino compounds and related substances on Aphanomyces root rot of peas. Phytopathology 53, 109.

Townsend, B. B. \& Willetrs, H. J. (1954). 'The development of sclerotia of certain fungi. Trans. Br. mycol. Soc. 37, 213.

West, E. (1947). Sclerotium rolfsii Sacc. and its perfect stage on climbing fig. Phytopathology 37, 67 .

WheELer, B. E. J. \& WALler, J. M. (1965). The production of sclerotia by Sclerotium rolfsii. II. The relationship between mycelial growth and initiation of sclerotia. Trans. Br. mycol. Soc. 48, 303.

\section{EXPLANATION OF PLATE}

Plate 1. Effect of L-cysteine and iodoacetic acid on Sclerotium rolfsii.

Fig. 1. Normal growth of $S$. rolfsii on defined medium agar after incubation for 10 days at $30^{\circ}$. Brown sclerotia are especially abundant at the edges of the Petri dish. $\times 0.66$.

Fig. 2. Growth of $S$. rolfsii in the presence of $10^{-2} \mathrm{M}-\mathrm{L}-\mathrm{cysteine}$. Mycelium is more dense than that seen in fig. 1 . Only two sclerotia are seen; linear growth is significantly restricted. $\times \mathbf{0 \cdot 6 6}$.

Fig. 3. Effect of $10^{-4} \mathrm{M}$-iodoacetic acid on growth pattern of $S$. rolfsii. Mycelium not affected, but sclerotia are formed in circles around the inoculum and are bigger than those seen in fig. 1. $\times 0.66$.

Fig. 4. Mutual inhibition of the effects of L-cysteine $\left(10^{-4} \mathrm{M}\right)$ and iodoacetic acid $\left(3 \times 10^{-5} \mathrm{M}\right)$. A normal growth of $S$. rolfsii is seen. $\times \mathbf{0 . 6 6}$. 

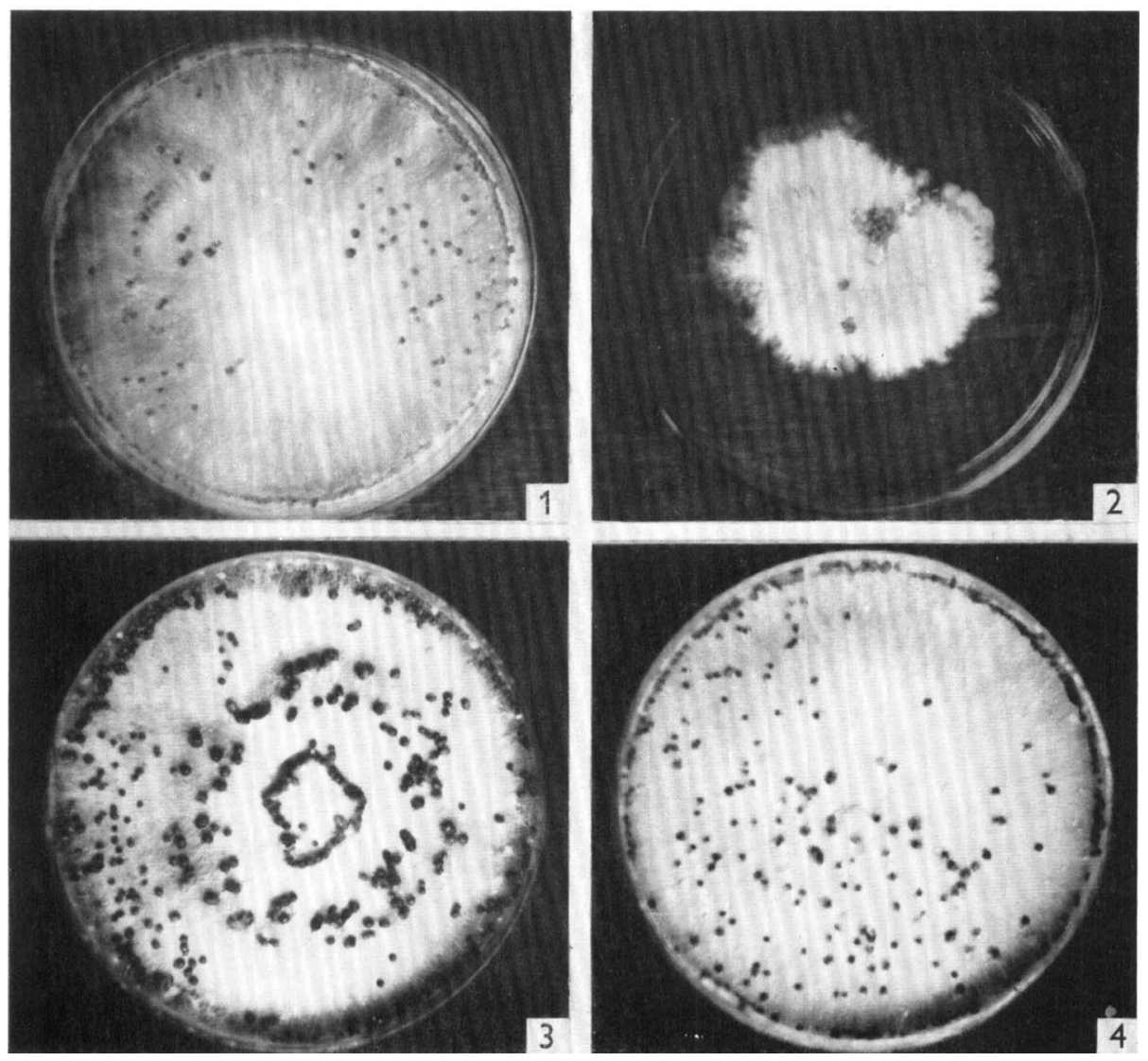